\title{
Assessment of Prevalence of Chronic Kidney Disease and Its Predisposing Factors in Kerman City
}

\author{
Azadeh Saber, ${ }^{1}$ Ahmad Naghibzadeh Tahami, ${ }^{2}$ Hamid Najafipour, ${ }^{3}$ and Jalal Azmandian ${ }^{4,}$ \\ ${ }^{1}$ Assistant Professor of Nephrology, Physiology Research Center, Institute of Neuropharmacoloy, Kerman University of Medical Sciences, Kerman, IR Iran \\ ${ }^{2}$ MSc in Epidemiology, Gastroenterology and Hepatology Research Center, Institute of Basic and Clinical Physiology Sciences, Kerman University of Medical Sciences, \\ Kerman, IR Iran \\ ${ }^{3}$ Professor of Physiology, Endocrinology and Metabolism Research Center, Institute of Basic and Clinical Physiology Sciences, Kerman University of Medical Sciences, Kerman, \\ IR Iran \\ ${ }^{4}$ Associate Professor of Nephrology, Cardiovascular Research Center, Institute of Basic and Clinical Physiology Sciences, Kerman University of Medical Sciences, Kerman, IR \\ Iran \\ "Corresponding author: Jalal Azmandian, Associate Professor of Nephrology, Cardiovascular Research Center, Institute of Basic and Clinical Physiology Sciences, Kerman \\ University of Medical Sciences, Kerman, IR Iran. E-mail: jazmandian@kmu.ac.ir
}

Received 2016 August 26; Revised 2016 October 22; Accepted 2017 January 21.

\begin{abstract}
Background: Chronic kidney disease (CKD) is a prevalent, progressive, and treatable disease. However, lack of enough data about its prevalence in Iran is a major obstacle for its early detection. In order to determine the prevalence of the disease in the country, it is necessary to conduct epidemiologic studies especially on populations with ethnic diversity; hence, this study aimed at determining the prevalence of CKD and its predisposing factors in an adult population aged 15 to 75 years old in Kerman city.

Methods: This cross-sectional study was conducted on 988 adults aged 15 to 75 years in Kerman city, during year 2010. We collected data on the status of hypertension (HTN) and Diabetes Mellitus (DM) in all participants. Moreover, height, weight, and blood pressure of all participants were measured and a blood sample was taken for laboratory tests. In addition, a morning urine sample was taken to detect microalbuminuria and measure protein, and creatinine. Patients' glomerular filtration rate (GFR) was calculated using modification of diet in renal disease (MDRD) formula, and the stage of the chronic kidney disease (CKD) was determined.

Results: Of all the participants, $58 \%$ were female and the mean age (SD) of participants was $45 \pm 16$ years. Considering participants' body mass index (BMI), 37\% were overweight and 18\% were obese. The prevalence of HTN and DM were $20 \%$ and $14 \%$, respectively. Mean GFR(SD) was $67 \pm 20 \mathrm{~mL} / \mathrm{min} / 1.73 \mathrm{~m}^{2}$. Overall, $91 \%$ of the participants were affected by some degree of CKD (stage 1:5\%; stage 2: 55.1\%; stage 3: 30.5\%; stage 4: 0.4\%). Prevalence of CKD that was defined through GFR < $60 \mathrm{cc} / \mathrm{min}$ was 30.9\%. The CKD stage was significantly higher in females, people over 50 years old, overweight or obese individuals, and participants with hypercholesterolemia, high LDL or HTN $(\mathrm{P}<0.05)$. However, CKD stage had no significant relationship with triglyceride level, HDL level, or DM (P > 0.05). Conclusions: The findings of the present study showed that $91 \%$ of the adult population living in Kerman city was affected by some degrees of CKD and more than one-third were at stages 3 or 4. Prevalence of CKD that was defined through GFR $<60 \mathrm{cc} / \mathrm{min}$ was 30.9\%. Since early detection of CKD could help adopt preventive measures and interventions, and prevent disease progression, policy makers must pay special attention to preventive programs, such as programs for life style modification, and design treatment plans for different risk factors, such as HTN, DM, and dyslipidemia.
\end{abstract}

Keywords: Chronic Kidney Disease, CKD, Prevalence, Risk Factors

\section{Introduction}

Chronic kidney disease (CKD) is a new term, which was introduced after the recognition of end stage renal disease (ESRD). In fact, ESRD is the end stage of CKD, which is associated with uremic syndrome and has a very poor prognosis. Chronic kidney disease is a condition that is characterized by the progressive loss of the kidneys' ability to maintain normal levels of protein metabolism products (such as urea), normal blood pressure, and normal level of hematocrit; it also disturbs the water balance and electrolyte and acid-base balance. Based on existing definitions, CKD refers to a structural or functional damage to kidneys that lasts for more than three months (1). It is calculated based on the glomerular filteration rate (GFR) rate, and considering its severity it is divided to stages 1 to 5 (2).

According to epidemiological studies, CKD has become a common and prevalent disease in the general population (3). It also has been found that CKD is a risk factor for many diseases, such as cardiovascular diseases (4), anemia (5), electrolyte abnormalities (6), bone diseases (7), and cognitive and psychological disorders (8). On the one hand, CKD progresses over time and its progress leads to new complications or worsens the effects of previous complications. On the other hand, it may be possible to take some measures and alter the progression of the disease and its complications $(8,9)$. However, because of the hidden nature 
of this disease, it is necessary to screen patients at an early stage $(10,11)$. Chronic kidney disease is a situation that can threaten health, economic, and social aspects of the life of the patient, their family, and community. Hence, in the recent years, it has received much attention, particularly in developed countries $(2,12)$.

Although extensive studies have been conducted in different countries to determine the prevalence of CKD, due to differences in methods of studies, the results have been substantially different. The most detailed study ever conducted in this field is the Third national health and nutrition examination survey (NHANES III) (13). According to the mentioned study, $13.1 \%$ of the adult population in the United States ie, about 26.3 million people are affected by CKD (13). The presence of ethnic and religious minorities, differences in age distribution, and differences in economic levels have an impact on the prevalence of CKD (14). According to previous reports, the prevalence of CKD in other countries has been diverse. The prevalence of CKD in the European countries has been reported from $4.2 \%$ in the Netherlands (15) to $24.7 \%$ in Iceland (16). The prevalence of the disease in people of older ages has been reported as up to $44.9 \%$ (17). In Asian countries, the prevalence of the disease has been $6.6 \%$ in Singapore (18), 20.4\% in China (19), and $28.8 \%$ in individuals older than 40 years in Japan (20). In a review study conducted in 2008 , the prevalence of CKD in people 30 years of age and older was $7.2 \%$, while in subjects 64 years of age and older it ranged from $23.4 \%$ to $35.8 \%$ (3).

In Iran, various studies have investigated the status of CKD in the country. The prevalence of CKD in Iran, during year 2004, was about 108.3 Per Million Population (PMP) and its incidence was estimated to be 17.35 PMP (21). The prevalence of CKD in Tehran was estimated to be about 18.9\% (22). In addition, its prevalence in the population aged over 14 years in all provinces was reported to be $12.6 \%$ (23). However, different prevalence rates have been reported by other studies (24-28).

Chronic kidney disease is a common, progressive, and treatable disease. However, the shortage of information about the prevalence of this disease in Iran is a major obstacle in pushing health systems and facilities towards early detection of the disease. It is necessary to conduct studies, especially on populations with ethnic diversity, to determine the epidemiology of the disease in the country. Hence, the aim of this study was to determine the prevalence of CKD and its risk factors in patients aged 15 to 75 years old in Kerman city.

\section{Methods}

This cross sectional descriptive study was conducted during year 2010 in the city of Kerman. The target population included people aged 15 to 75 years old, who were living in the city of Kerman for at least the previous year. Taking into account a confidence interval of $95 \%$ and the prevalence of CRF in the US, which is 13\% (3), the sample size was calculated as 988 people. The subjects were selected via the single-stage cluster sampling method, which was based on postcodes. The most recent postcode list was obtained from the post office and taking into consideration the population density, a total of 40 postal codes were randomly selected as the cluster heads. Each cluster had a sample size of 24 people. Trained health coordinators visited every household in the clusters and invited the subjects to complete a questionnaire and perform the tests. When a person did not accept the invitation, the researcher visited a neighboring home on the right side; this process continued until the entire cluster sample size of eligible persons was completed. Moreover, in case, after a face-to-face invitation and two phone calls, a person did not visit the center to complete the questionnaire and do the tests, he or she was substituted with another qualified person selected from another neighboring home on the right side.

A physician completed a questionnaire for every participant; the questionnaire included questions about demographic data (age, gender, education, and marital status), hypertension, diabetes, and a family history of hypertension and diabetes. In addition, the physician performed a physical examination to investigate edema in the body. Height, weight, and blood pressure of all the subjects was measured and $2 \mathrm{~mL}$ of blood sample was taken from all cases to measure fasting blood sugar (FBS), blood urea nitrogen (BUN), creatinine ( $\mathrm{Cr}$ ), cholesterol, triglycerides, low-density lipoprotein (LDL), and high-density lipoprotein (HDL). In patients with the Stage 1 kidney failure, the level of GFR still remained normal, hence the diagnosis of CKD was possible through the measurement of albuminuria in the urine samples. Given that the detection of microalbuminuria is possible via testing random urine samples, morning urine samples were taken from all subjects and the level of protein and creatinine were measured. Furthermore, using the formula of modification of diet in renal disease $($ MDRD $)\left(\right.$ GFR $\left(\mathrm{mL} / \mathrm{min} / 1.73 \mathrm{~m}^{2}\right)=186 \times($ Serum $\mathrm{Cr})^{-1.154} \times(\text { Age })^{-0.203} \times(0.742$ if female $\left.)\right)$, GFR was calculated for all the subjects (29) and based on the results, people with abnormal GFR were divided to 5 categories, as follows:

Stages 1: GFR $\geq 90 \mathrm{~mL} / \mathrm{min}$ and persistent albuminuria

Stages 2: GFR 60 - $89 \mathrm{~mL} / \mathrm{min}$ and persistent albuminuria

Stages 3: GFR $30-59 \mathrm{~mL} / \mathrm{min}$ 
Stages 4: GFR 15 - $29 \mathrm{~mL} / \mathrm{min}$

Stages 5: GFR $<15 \mathrm{~mL} / \mathrm{min}$

Those with GFR $\geq 90 \mathrm{~mL} / \mathrm{min}$, yet, without any of the mentioned risk factors were considered as normal cases (Stage 0).

Statistical analysis was performed using the SPSS 22 software. Frequency (\%) and the mean (Standard Deviation), respectively, were used for describing qualitative and quantitative variables. Chi-square test was used to compare the frequency of findings in the two genders, age groups, and different stages of chronic kidney disease. The significance level was set at $\mathrm{P}<0.05$.

\section{Results}

From the total of 988 participants, who took part in this study, $58 \%$ were female. The age range and mean age (SD) of the subjects were 15 to 85 years old and $45 \pm 16$ years, respectively. Half of them had an educational degree below high school diploma and $83 \%$ were married (Table 1 ). Table 1 also shows the participants' blood pressure and anthropometric characteristics. Considering the body mass index (BMI), 64 patients (6\%) had a BMI lower than 18.5, 383 patients (39\%) had normal BMI (18.5 to 25), 362 patients (37\%) were overweight (25 to 30 ), and 179 patients (18\%) were obese $(>30)$. According to the results of physical examination, 304 patients (31\%) had $1+$ edema and 31 patients $(3 \%)$ had $2+$ edema. The prevalence of high blood pressure in mother, father, brother, sister, and children of the participants was $14 \%, 34 \%, 8 \%, 14 \%$, and $2 \%$, respectively. Moreover, the prevalence of diabetes in father, mother, brother, sister, and children of the participants was $8 \%, 19 \%, 6 \%, 11 \%$ and $2 \%$, respectively. Table 2 shows the results of tests performed for the participants. Table 3 shows the lipid profile and the prevalence of high blood pressure and diabetes in the participants.

The mean (SD) of GFR, which was calculated using the MDRD formula, was $67 \pm 20 \mathrm{~mL} / \mathrm{min} / 1.73 \mathrm{~m}^{2}$. Table 4 shows the status of chronic kidney disease based on the GFR of the participants. According to the results, 91\% of the studied population had some degree of chronic kidney disease and over a third of them were in stages 3 and 4 . Prevalence of CKD, defined through GFR < 60 cc/min, was 30.9\%.

Table 5 compares the status of BMI, lipids profile, hypertension, and diabetes between the two genders and between the two age groups. Overweight and obesity were significantly more prevalent in females than males; they were also more prevalent in people older than 50 years of age than in people 50 years old or younger $(\mathrm{P}<0.001)$. High cholesterol, high triglycerides, and high LDL were significantly higher in females, whereas low HDL was significantly higher in males $(\mathrm{P}<0.05)$. Moreover, the preva-
Table 1. Demographic and Anthropometric Characteristics and Blood Pressure of Participants ${ }^{\mathrm{a}}$

\begin{tabular}{|c|c|}
\hline & Values \\
\hline \multicolumn{2}{|l|}{ Gender } \\
\hline Male & $420(42)$ \\
\hline Female & $568(58)$ \\
\hline \multicolumn{2}{|l|}{ Age, $y$} \\
\hline$\leq 50$ & $61(63)$ \\
\hline$>50$ & $369(37)$ \\
\hline \multicolumn{2}{|l|}{ Education } \\
\hline Lower than diploma & $489(50)$ \\
\hline Diploma or upper & $499(50)$ \\
\hline \multicolumn{2}{|l|}{ Marital status } \\
\hline Married & $815(83)$ \\
\hline Single & $173(17)$ \\
\hline Weight, kg & $70 \pm 14$ \\
\hline Range & $32-143$ \\
\hline Height, $\mathrm{cm}$ & $164 \pm 10$ \\
\hline Range & $118-195$ \\
\hline BMI & $25.8 \pm 5$ \\
\hline Range & $14.7-54.9$ \\
\hline Systolic blood pressure, mmHg & $116 \pm 20$ \\
\hline Range & $80-200$ \\
\hline diastolic blood pressure, $\mathrm{mmHg}$ & $77 \pm 9$ \\
\hline Range & $40-120$ \\
\hline
\end{tabular}

${ }^{\mathrm{a}}$ Values are expressed as Mean $\pm \mathrm{SD}$ or No. (\%).

Table 2. Laboratory Test Results

\begin{tabular}{lcc}
\hline & Range & Mean $\pm \mathbf{S D}$ \\
\hline FBS, $\mathbf{m g} / \mathbf{d L}$ & $60-367$ & $101 \pm 41$ \\
\hline BUN, $\mathbf{m g} / \mathbf{d L}$ & $2-92$ & $31 \pm 10$ \\
\hline Creatinine, $\mathbf{m g} / \mathbf{d L}$ & $0.3-3.3$ & $1.1 \pm 0.2$ \\
\hline Cholesterol, $\mathbf{m g} / \mathbf{d L}$ & $26-374$ & $193 \pm 43$ \\
\hline Triglyceride, $\mathbf{m g} / \mathbf{d L}$ & $32-750$ & $146 \pm 90$ \\
\hline LDL, mg/dL & $33-302$ & $125 \pm 34$ \\
\hline HDL, $\mathbf{m g} / \mathbf{d L}$ & $21-187$ & $40 \pm 11$ \\
\hline Urine protein, $\mathbf{m g} / \mathbf{d L}$ & $0.02-128$ & $44 \pm 10$ \\
\hline Urine creatinine, $\mathbf{m g} / \mathbf{d L}$ & $0.04-1302$ & $1203 \pm 127$ \\
\hline
\end{tabular}

lence of hypertension was significantly higher in females $(\mathrm{P}<0.05)$. Nevertheless, the prevalence of diabetes mellitus was not different between the males and females $(\mathrm{P}>$ 
Table 3. Lipids Profile Status and Prevalence of Hypertension and Diabetes Mellitus

\begin{tabular}{lc}
\hline & No $(\%)$ \\
\hline High cholesterol, $>\mathbf{2 0 0} \mathbf{m g} / \mathbf{d L}$ & $399(40)$ \\
\hline High triglyceride, $>\mathbf{1 5 0 m g / d L}$ & $362(37)$ \\
\hline High LDL, $>\mathbf{1 3 0} \mathbf{m g} / \mathbf{d L}$ & $399(40)$ \\
\hline Low HDL, $<\mathbf{4 0 m g / d L ~ i n ~ m e n , ~}<\mathbf{5 0 m g / d L ~ i n ~ w o m e n ~}$ & $621(63)$ \\
\hline Hypertension & $198(20)$ \\
\hline Diabetes & $136(14)$ \\
\hline
\end{tabular}

Table 4. Chronic Kidney Disease Status Based on Glomerular Filtration Rate

\begin{tabular}{lc}
\hline Stage & No(\%) \\
\hline $\mathbf{0}$ & $88(9)$ \\
$\mathbf{1}$ & $49(5)$ \\
$\mathbf{2}$ & $545(55.1)$ \\
$\mathbf{3}$ & $301(30.5)$ \\
\hline
\end{tabular}

0.05). Furthermore, people over 50 years of age had significantly higher levels of cholesterol, triglycerides, high LDL, and low HDL; the prevalence of hypertension and diabetes was also higher in this age group $(\mathrm{P}<0.05)$.

Table 6 compares the relationship between different stages of chronic kidney disease and gender, age group, BMI, lipids profile, hypertension, and diabetes. Females were significantly more commonly found with higher stages of CKD than males. In addition, CKD stages were significantly higher in older people $(\mathrm{P}<0.05)$. Moreover, $\mathrm{CKD}$ stages were significantly higher in obese and overweight patients than in normal weight and underweight patients $(\mathrm{P}<0.001)$. People with high cholesterol and high LDL were significantly at higher stages of CKD $(\mathrm{P}<0.05)$, however, triglycerides and HDL levels had no significant relationship with the frequency of different stages of the disease $(P>0.05)$. Chronic kidney disease stages were significantly higher in people with hypertension than in people with normal blood pressure $(\mathrm{P}<0.001)$, while diabetes had no significant relationship with the frequency of different stages of the disease $(\mathrm{P}>0.05)$.

\section{Discussion}

The findings of this study showed that $91 \%$ of patients aged 15 to 75 years old in Kerman city had some degrees of CKD and more than a third of them were at stages 3 and 4 . Prevalence of CKD, defined through GFR $<60 \mathrm{cc} / \mathrm{min}$, was $30.9 \%$.
High cholesterol, high triglycerides, and high LDL were more prevalent in females while low HDL was more prevalent in males. Hypertension was more prevalent in females; however, the prevalence of diabetes was not significantly different between the two genders. Moreover, high cholesterol, high triglycerides, high LDL, and low HDL were higher, hypertension, and diabetes were more prevalent in individuals older than 50 years of age. The higher stages of the disease were more prevalent in females than in males and in individuals aged over 50 years than younger individuals. Overweight or obese individuals, those who had high cholesterol, high LDL, and hypertension were at higher stages of the disease. Triglycerides, HDL, and diabetes did not have a relationship with the prevalence of different stages of the disease.

So far, many studies have been conducted in various countries to determine the prevalence of CKD and its predisposing factors. However, because of the utilization of different methods and sample size, place of residence, genetics, and age, the results have many notable differences. Nevertheless, according to the reports, the incidence of CKD in different areas is rising. According to the KEEP study in America, the prevalence of CKD was estimated $15.6 \%$ in 2005 (30). It has been also reported that the prevalence of CKD stages 1 to 4 in America increased from 10\%, in 1988 to 1994, to $13.1 \%$ in 1999 to 2004 (31). According to the NHANES III study, the prevalence of the disease in the adult population of the United States was 13.1\%; moreover, $1.78 \%$ of patients were in stage $1,3.24 \%$ were in stage $2,7.69 \%$ were in stage 3 , and $0.35 \%$ were in stage 4 (13). In Mexico, the prevalence of CKD in the population over 18 years of age was $8.5 \%$ (32). According to other studies, the prevalence of CKD was $6.4 \%$ in Italy (33), 4.7\% in Norway (34), 8.1\% in Switzerland (35), 5.1\% in Spain (36), 4.2\% in Netherlands (15), and 7.2$24.7 \%$ in Iceland (16).

The prevalence of CKD in Asian countries is reported as follows: $20.4 \%$ in China (19), $6.8 \%$ in Thailand (37), $6.6 \%$ in Singapore (18), 5.7\% in Saudi Arabia (38), and 11.2\% - 12\% in Australia (39, 40). According to a review study by Zhang and Rothenbacher in 2008, CKD is going to be a common disease in the general population, however, it has a poor diagnosis in different populations, especially in the elderly, females, and certain ethnic groups (3).

Although there is no exact epidemiologic information on the prevalence of CKD in Iran, some studies have investigated the status of CKD in the country. Nafar et al. in 2008 conducted a study and reviewed the data on chronic diseases registered in 2004, and also reviewed scattered reports on the status of CKD in Iran. According to their findings, there were about 700,000 CKD patients in 2004. It seems that every year 61,000 new cases are added. The prevalence of CKD in Iran in 2004 was about 108.3 PMP and 
Table 5. Comparison of Body Mass Index Status, Lipids Profile Status, Hypertension and Diabetes Prevalence Between Gender and Age Groups

\begin{tabular}{|c|c|c|c|c|c|c|}
\hline & \multicolumn{3}{|c|}{ Gender } & \multicolumn{3}{|c|}{ Age, $y$} \\
\hline & Male $(n=420)$ & Female $(n=528)$ & PValue $^{\mathbf{a}}$ & $<=50(n=629)$ & $>50(n=369)$ & P Value $^{\mathbf{a}}$ \\
\hline \multicolumn{7}{|l|}{ BMI Status } \\
\hline Underweight & $35(8)$ & $29(5)$ & \multirow{4}{*}{$<0.001$} & $55(9)$ & $9(2)$ & \multirow{4}{*}{$<0.001$} \\
\hline Normal & $197(47)$ & $187(33)$ & & $253(41)$ & $131(35)$ & \\
\hline Overweight & $148(35)$ & $215(38)$ & & $214(34)$ & $149(41)$ & \\
\hline Obese & $41(10)$ & $139(24)$ & & $99(16)$ & $81(22)$ & \\
\hline High Cholesterol & $145(35)$ & $254(45)$ & 0.001 & $191(31)$ & $208(56)$ & $<0.001$ \\
\hline High triglyceride & $174(42)$ & $188(33)$ & 0.007 & $191(31)$ & $171(46)$ & $<0.001$ \\
\hline High LDL & $144(35)$ & $255(45)$ & 0.001 & $194(31)$ & $205(56)$ & $<0.001$ \\
\hline Low HDL & $383(91)$ & $238(42)$ & $<0.001$ & $373(60)$ & $248(67)$ & 0.029 \\
\hline Hypertension & $70(17)$ & $128(33)$ & 0.023 & $49(8)$ & $149(40)$ & $<0.001$ \\
\hline Diabetes & $52(12)$ & $84(15)$ & 0.278 & $37(6)$ & $99(27)$ & $<0.001$ \\
\hline
\end{tabular}

${ }^{\mathrm{a}}$ Chi square test.

Table 6. Comparison of Demographic Characteristics, Body Mass Index Status, Lipids Profile Status, Hypertension and Diabetes Prevalence Among Chronic Kidney Disease Stages

\begin{tabular}{|c|c|c|c|c|c|}
\hline & & \multicolumn{3}{|c|}{ Chronic Kidney Disease Stages } & \multirow[t]{2}{*}{ P Value $^{\mathrm{a}}$} \\
\hline & & Stage 0 & Stage 1-2 & Stage 3 - 4 & \\
\hline \multirow{2}{*}{ Gender } & Male & $13(3)$ & $292(70)$ & $115(27)$ & \multirow{2}{*}{$<0.001$} \\
\hline & Female & $10(2)$ & $303(58)$ & $228(40)$ & \\
\hline \multirow{2}{*}{ Age, $y$} & $\leq 50$ & $18(3)$ & $426(69)$ & $175(28)$ & \multirow{2}{*}{$<0.001$} \\
\hline & $>50$ & $5(1)$ & $196(53)$ & $168(46)$ & \\
\hline \multirow{4}{*}{ BMI Status } & Underweight & $2(3)$ & $54(84)$ & $8(13)$ & \multirow{4}{*}{$<0.001$} \\
\hline & Normal & $10(3)$ & $269(70)$ & $104(27)$ & \\
\hline & Overweight & $8(2)$ & $202(56)$ & $152(42)$ & \\
\hline & Obese & $3(2)$ & $97(54)$ & $79(44)$ & \\
\hline \multirow{2}{*}{ Cholesterol } & High & $4(1)$ & $231(58)$ & $164(41)$ & \multirow{2}{*}{$<0.001$} \\
\hline & Normal & $19(3)$ & $391(67)$ & $179(30)$ & \\
\hline \multirow{2}{*}{ Triglyceride } & High & $6(2)$ & $227(63)$ & $129(35)$ & \multirow{2}{*}{0.536} \\
\hline & Normal & $17(3)$ & $395(63)$ & $214(34)$ & \\
\hline \multirow{2}{*}{ LDL } & High & $3(1)$ & $238(60)$ & $158(39)$ & \multirow{2}{*}{0.002} \\
\hline & Normal & $20(3)$ & $384(65)$ & $185(32)$ & \\
\hline \multirow{2}{*}{ HDL } & Low & $13(2)$ & $405(65)$ & $203(33)$ & \multirow{2}{*}{0.155} \\
\hline & Normal & $10(3)$ & $217(59)$ & $140(38)$ & \\
\hline \multirow{2}{*}{ Blood Pressure } & High & $3(2)$ & $95(48)$ & $100(50)$ & \multirow{2}{*}{$<0.001$} \\
\hline & Normal & $20(3)$ & $527(67)$ & $243(30)$ & \\
\hline \multirow{2}{*}{ Diabetes } & Yes & $1(1)$ & $81(60)$ & $54(39)$ & \multirow{2}{*}{0.208} \\
\hline & No & $22(3)$ & $541(64)$ & $289(33)$ & \\
\hline
\end{tabular}

${ }^{\mathrm{a}}$ Chi square test.

its incidence was 17.35 PMP (21). Safarinejad conducted a study in 30 provinces of Iran from 2002 to 2005 and evaluated a total of 16354 individuals older than 14 years of age with a mean age of 51 years. According to the results of the mentioned study, $12.6 \%$ of the study population was diagnosed with CKD, of whom $2.2 \%$ were in stage $1,2.1 \%$ were in stage $2,7.8 \%$ were in stage $3,0.3 \%$ were in stage 4 , and $0.2 \%$ were in stage 5 . In addition, the estimated prevalence of the disease in the provinces of Kerman and Hormozgan was $15 \%$ to $17 \%$ (23). Hosseinpanah et al. during years 1997 to 2000 , conducted a cross sectional study on 10063 people over 20 years of age with a mean age of 42 years, who were living in Tehran. According to the results, the prevalence of CKD was about $18.9 \%$. However, the mentioned study only investigated stages 3, 4, and 5 (22). Ghafari et al. studied 905 patients with CKD risk factors in Urmia 
and the surrounding villages, and according to their findings the prevalence rates of elevated creatinine and proteinuria were $37.9 \%$ and $23.4 \%$, respectively (24). According to the study of Ebrahimi et al. the prevalence of disease in Isfahan was 4.6\% (41). Tohidi et al. conducted a 10year prospective cohort study on 3,313 adults aged 20 years and older, who were not affected by CKD. According to their findings, the cumulative incidence of CKD in females and males, respectively, was 285.3 and 132.6 per 10,000 personyears. They noted that more than $2 \%$ of people each year are diagnosed with CKD (25). Najafi et al. conducted a study on 1,557 people aged 18 years and older. According to their results, which were calculated using MDRD formula, the prevalence of CKD stages 3 to 5 was $8.89 \%$. Considering the urinary sediment abnormalities, the prevalence of CKD stages 1 and 2 was 10.63\%, while based on macro and microalbuminuria test the prevalence was $14.53 \%$ (26). According to the results of Naghibi et al.'s study, the prevalence of CKD (GFR less than $60 \mathrm{~mL} / \mathrm{min} / 1.73 \mathrm{~m}^{2}$ ) in 1285 individuals aged 20 to 60 years old in Gonabad was 5.1\% (28). Khajehdehi et al. in 2014 conducted a study on 10385 people in southern part of Iran and found that the prevalence rates of CKD stages 1, 2, 3, 4, and 5, respectively, were 8.5\%, $66.1 \% 11.4 \%, 0.1 \%$, and $0.1 \%$ (27). The findings of our study showed that $91 \%$ of patients aged 15 to 75 years old in Kerman had some degree of CKD and the prevalence of CKD stages $1,2,3$, and 4 , respectively, were $5 \%, 55.1 \%, 30.5 \%$, and $0.4 \%$. Compared with other studies in the country, the results of our study indicated the high prevalence of CKD in the city of Kerman. The differences in the study results can be attributed to the use of different methods, for instance some studies measure creatinine while other studies measure GFR; in addition, studies may use different criteria for CKD or choose different types of study populations. Nevertheless, the prevalence rate obtained in our study is partly consistent with the rates reported by Khajehdehi et al. in southern part of Iran (27). However, the prevalence of stage 3 CKD in our study is nearly three times more than the rate reported by Khajehdehi et al. and Ghaffari et al. Given that CKD is asymptomatic in its early stages and since it can be prevented via using some interventions, it is necessary to take appropriate intervention measures and conduct regular screening to identify patients at risk and to treat them.

So far, many studies have investigated the risk factors for CKD (42-46). Our study showed that higher stages of the disease were more common in females, people over 50 years of age, overweight or obese people, and people with high cholesterol, high LDL, and hypertension. However, the disease stages did not have a relationship with triglycerides, HDL, and diabetes. Stage 2 kidney failure had the highest prevalence in this sample, which is in agreement with nephrology references. The incidence of higher stages of CKD in the above-mentioned conditions suggests that low physical activity is one of the most important factors for the development of CKD and its higher stages. Thus, it seems necessary to change lifestyle and treat different risk factors such as hypertension, diabetes, and dyslipidemia, to reduce the risk of CKD or improve its symptoms. Therefore, it is recommended to design and implement preventive and curative programs at the community level, especially in populations with a high prevalence of disease, such as Kerman; these programs could be part of primary care. Moreover, further epidemiologic studies on a regular basis are needed to evaluate the effectiveness of these measures.

\subsection{Conclusions}

The findings of this study showed that $91 \%$ of patients aged 15 to 75 years old in Kerman had some degrees of CKD and more than a third of them were at stages 3 and 4 . Prevalence of CKD, defined through GFR < $60 \mathrm{cc} / \mathrm{min}$, was $30.9 \%$.

In addition, higher stages of the disease were more common in females, people over 50 years of age, overweight or obese people, and people with high cholesterol, high LDL, and hypertension. Stage 2 kidney failure had the highest prevalence in this sample, which is in agreement with nephrology references. However, the disease stages did not have a relationship with triglycerides, HDL, and diabetes. Because of the high prevalence of CKD, in order to reduce the risk of CKD or improve its stages, it is necessary to adopt and run preventive and curative programs at the community level, especially in populations with a high prevalence of the disease, such as Kerman, to alter people's lifestyle and deal with the related risk factors. Further studies may also be needed to evaluate the effectiveness of the adopted policies and programs.

\section{References}

1. Lederer E, Ouseph R. Chronic kidney disease. Am J Kidney Dis 2007;49(1):162-71. doi: 10.1053/j.ajkd.2006.09.021. [PubMed: 17185158].

2. Levey AS, Eckardt KU, Tsukamoto Y, Levin A, Coresh J, Rossert J, et al. Definition and classification of chronic kidney disease: a position statement from Kidney Disease: Improving Global Outcomes (KDIGO). Kidney Int. 2005;67(6):2089-100. doi: 10.1111/j.15231755.2005.00365.x. [PubMed: 15882252].

3. Zhang QL, Rothenbacher D. Prevalence of chronic kidney disease in population-based studies: systematic review. BMC Public Health. 2008;8:117. doi: 10.1186/1471-2458-8-117. [PubMed: 18405348].

4. Chin HJ, Ahn JM, Na KY, Chae DW, Lee TW, Heo NJ, et al. The effect of the World Kidney Day campaign on the awareness of chronic kidney disease and the status of risk factors for cardiovascular disease and renal progression. Nephrol Dial Transplant. 2010;25(2):413-9. doi: 10.1093/ndt/gfp512. [PubMed: 19783595].

5. Clement FM, Klarenbach S, Tonelli M, Johnson JA, Manns BJ. The impact of selecting a high hemoglobin target level on health-related quality of life for patients with chronic kidney disease: a systematic 
review and meta-analysis. Arch Intern Med. 2009;169(12):1104-12. doi: 10.1001/archinternmed.2009.112. [PubMed:19546410].

6. Leal VO, Delgado AG, Leite M Jr, Mitch WE, Mafra D. Influence of renal function and diet on acid-base status in chronic kidney disease patients. J Ren Nutr. 2009;19(2):178-82. doi: 10.1053/j.jrn.2008.08.010. [PubMed: 19218046].

7. Kovesdy CP, Kalantar-Zadeh K. Bone and mineral disorders in predialysis CKD. Int Urol Nephrol. 2008;40(2):427-40. doi: 10.1007/s11255008-9346-7. [PubMed: 18368510].

8. Elias MF, Elias PK, Seliger SL, Narsipur SS, Dore GA, Robbins MA. Chronic kidney disease, creatinine and cognitive functioning. Nephrol Dial Transplant. 2009;24(8):2446-52. doi: 10.1093/ndt/gfp107. [PubMed: 19297357].

9. Bolignano D, Palmer SC, Navaneethan SD, Strippoli GF. Aldosterone antagonists for preventing the progression of chronic kidney disease. Cochrane Database Syst Rev. 2014(4):CD007004. doi: 10.1002/14651858.CD007004.pub3. [PubMed: 24782282].

10. Kiberd B. The chronic kidney disease epidemic: stepping back and looking forward. J Am Soc Nephrol. 2006;17(11):2967-73. doi: 10.1681/ASN.2006020123. [PubMed: 17035615].

11. Rao M, Pereira BJ. Chronic kidney disease in India-a hidden epidemic. Indian J Med Res. 2007;126(1):6.

12. Bello AK, Nwankwo E, El Nahas AM. Prevention of chronic kidney disease: a global challenge. Kidney Int Suppl. 2005(98):S11-7. doi: 10.1111/j.1523-1755.2005.09802.x. [PubMed: 16108964].

13. Clase CM, Kiberd BA, Garg AX. Relationship between glomerular filtration rate and the prevalence of metabolic abnormalities: results from the Third National Health and Nutrition Examination Survey (NHANES III). Nephron Clin Pract. 2007;105(4):c178-84. doi: 10.1159/000100489. [PubMed: 17347576].

14. Selvin E, Manzi J, Stevens LA, Van Lente F, Lacher DA, Levey AS, et al. Calibration of serum creatinine in the National Health and Nutrition Examination Surveys (NHANES) 1988-1994, 1999-2004. Am J Kidney Dis. 2007;50(6):918-26. doi: 10.1053/j.ajkd.2007.08.020. [PubMed: 18037092].

15. Verhave JC, Gansevoort RT, Hillege HL, Bakker SJ, De Zeeuw D, de Jong $\mathrm{PE}$, et al. An elevated urinary albumin excretion predicts de novo development of renal function impairment in the general population. Kidney Int Suppl. 2004(92):S18-21. doi: 10.1111/j.1523-1755.2004.09205.x. [PubMed: 15485409].

16. Viktorsdottir O, Palsson R, Andresdottir MB, Aspelund T, Gudnason $\mathrm{V}$, Indridason OS. Prevalence of chronic kidney disease based on estimated glomerular filtration rate and proteinuria in Icelandic adults. Nephrol Dial Transplant. 2005;20(9):1799-807. doi: 10.1093/ndt/gfh914. [PubMed: 15928100].

17. Brugts JJ, Knetsch AM, Mattace-Raso FU, Hofman A, Witteman JC. Renal function and risk of myocardial infarction in an elderly population: the Rotterdam Study. Arch Intern Med. 2005;165(22):2659-65. doi: 10.1001/archinte.165.22.2659. [PubMed:16344425].

18. Shankar A, Klein R, Klein BE. The association among smoking, heavy drinking, and chronic kidney disease. Am J Epidemiol. 2006;164(3):263-71. doi: 10.1093/aje/kwj173. [PubMed: 16775042].

19. Chen J, Wildman RP, Gu D, Kusek JW, Spruill M, Reynolds K, et al. Prevalence of decreased kidney function in Chinese adults aged 35 to 74 years. Kidney Int. 2005;68(6):2837-45. doi: 10.1111/j.15231755.2005.00757.x. [PubMed: 16316361].

20. Konta T, Hao Z, Abiko H, Ishikawa M, Takahashi T, Ikeda A, et al. Prevalence and risk factor analysis of microalbuminuria in Japanese general population: the Takahata study. Kidney Int. 2006;70(4):751-6. doi: 10.1038/sj.ki.5001504. [PubMed: 16807548].

21. Nafar M, Mousavi SM, Mahdavi-Mazdeh M, Pour-Reza-Gholi F, Firoozan A, Einollahi B, et al. Burden of chronic kidney disease in Iran: a screening program is of essential need. Iran J Kidney Dis. 2008;2(4):183-92. [PubMed: 19377235].

22. Hosseinpanah F, Kasraei F, Nassiri AA, Azizi F. High prevalence of chronic kidney disease in Iran: a large population-based study.
BMC Public Health. 2009;9:44. doi: 10.1186/1471-2458-9-44. [PubMed: 19183493].

23. Safarinejad MR. The epidemiology of adult chronic kidney disease in a population-based study in Iran: prevalence and associated risk factors. J Nephrol. 2009;22(1):99-108. [PubMed: 19229824].

24. Ghafari A, Ahmadnezhad E, Sepehrvand N, Hatami S, Zafarshamspoor S, Ayubian B, et al. Screening for asymptomatic kidney disease in high-risk population of Urmia, Iran. Iran J Kidney Dis. 2010;4(4):307-11. [PubMed: 20852372].

25. Tohidi M, Hasheminia M, Mohebi R, Khalili D, Hosseinpanah F, Yazdani $\mathrm{B}$, et al. Incidence of chronic kidney disease and its risk factors, results of over 10 year follow up in an Iranian cohort. PLoS One. 2012;7(9):e45304. doi: 10.1371/journal.pone.0045304. [PubMed: 23028919].

26. Najafi I, Shakeri R, Islami F, Malekzadeh F, Salahi R, Yapan-Gharavi $\mathrm{M}$, et al. Prevalence of chronic kidney disease and its associated risk factors: the first report from Iran using both microalbuminuria and urine sediment. Arch Iran Med. 2012;15(2):70-5. [PubMed: 22292573].

27. Khajehdehi P, Malekmakan L, Pakfetrat M, Roozbeh J, Sayadi M. Prevalence of chronic kidney disease and its contributing risk factors in southern Iran: a cross-sectional adult population-based study. Iran J Kidney Dis. 2014;8(2):109-15. [PubMed: 24685733].

28. Naghibi M, Mojahedi MJ, Jarrahi L, Emadzadeh A, Ahmadi R, Emadzadeh M, et al. Prevalence of chronic kidney disease and its risk factors in Gonabad, Iran. Iran J Kidney Dis. 2015;9(6):449-53. [PubMed: 26552351].

29. Levey AS, Stevens LA, Schmid CH, Zhang YL, Castro AF 3rd, Feldman HI, et al. A new equation to estimate glomerular filtration rate. Ann Intern Med. 2009;150(9):604-12. [PubMed: 19414839].

30. Brown WW, Peters RM, Ohmit SE, Keane WF, Collins A, Chen SC, et al. Early detection of kidney disease in community settings: the Kidney Early Evaluation Program (KEEP). Am J Kidney Dis. 2003;42(1):22-35. [PubMed: 12830453].

31. Coresh J, Selvin E, Stevens LA, Manzi J, Kusek JW, Eggers P, et al. Prevalence of chronic kidney disease in the United States. JAMA. 2007;298(17):2038-47. doi: 10.1001/jama.298.17.2038. [PubMed: 17986697].

32. Amato D, Alvarez-Aguilar C, Castaneda-Limones R, Rodriguez E, AvilaDiaz M, Arreola F, et al. Prevalence of chronic kidney disease in an urban Mexican population. Kidney Int Suppl. 2005(97):S11-7. doi: 10.1111/j.1523-1755.2005.09702.x. [PubMed: 16014087].

33. Cirillo M, Laurenzi M, Mancini M, Zanchetti A, Lombardi C, De Santo NG. Low glomerular filtration in the population: prevalence, associated disorders, and awareness. Kidney Int. 2006;70(4):800-6. doi: 10.1038/sj.ki.5001641. [PubMed: 16820784].

34. Hallan SI, Coresh J, Astor BC, Asberg A, Powe NR, Romundstad S, et al. International comparison of the relationship of chronic kidney disease prevalence and ESRD risk. J Am Soc Nephrol. 2006;17(8):2275-84. doi: 10.1681/ASN.2005121273. [PubMed: 16790511].

35. Nitsch D, Felber Dietrich D, von Eckardstein A, Gaspoz JM, Downs SH, Leuenberger $\mathrm{P}$, et al. Prevalence of renal impairment and its association with cardiovascular risk factors in a general population: results of the Swiss SAPALDIA study. Nephrol Dial Transplant. 2006;21(4):93544. doi: 10.1093/ndt/gfk021. [PubMed: 16390852].

36. Otero A, Gayoso P, Garcia F, de Francisco AL, Epirce study group . Epidemiology of chronic renal disease in the Galician population: results of the pilot Spanish EPIRCE study. Kidney Int Suppl. 2005(99):S169. doi: 10.1111/j.1523-1755.2005.09904.x. [PubMed: 16336570].

37. Domrongkitchaiporn S, Sritara P, Kitiyakara C, Stitchantrakul W, Krittaphol V, Lolekha P, et al. Risk factors for development of decreased kidney function in a southeast Asian population: a 12-year cohort study. J Am Soc Nephrol. 2005;16(3):791-9. doi: 10.1681/ASN.2004030208. [PubMed: 15677313].

38. Alsuwaida AO, Farag YM, Al Sayyari AA, Mousa D, Alhejaili F, Al-Harbi A, et al. Epidemiology of chronic kidney disease in the Kingdom of 
Saudi Arabia (SEEK-Saudi investigators) - a pilot study. Saudi J Kidney Dis Transpl. 2010;21(6):1066-72. [PubMed: 21060175].

39. McDonald SP, Maguire GP, Hoy WE. Renal function and cardiovascular risk markers in a remote Australian Aboriginal community. Nephrol Dial Transplant. 2003;18(8):1555-61. [PubMed: 12897094].

40. Chadban SJ, Briganti EM, Kerr PG, Dunstan DW, Welborn TA, Zimmet PZ, et al. Prevalence of kidney damage in Australian adults: The AusDiab kidney study. J Am Soc Nephrol. 2003;14(7 Suppl 2):S131-8. [PubMed: 12819318].

41. Barahimi H, Najafi I, Esmailian R, Rajaee F, Amini M, Ganji MR. Distribution of albuminuria and low glomerular filtration rate in a rural area, Shahreza, Iran. Iran J Kidney Dis. 2011;5(6):374-9. [PubMed: 22057068].

42. Haroun MK, Jaar BG, Hoffman SC, Comstock GW, Klag MJ, Coresh J. Risk factors for chronic kidney disease: a prospective study of 23,534 men and women in Washington County, Maryland. J Am Soc Nephrol. 2003;14(11):2934-41. [PubMed: 14569104].

43. Abrass CK. Overview: obesity: what does it have to do with kidney disease?. J Am Soc Nephrol. 2004;15(11):2768-72. doi: 10.1097/01.ASN.0000141963.04540.3E. [PubMed: 15504929].

44. Fox CS, Larson MG, Leip EP, Meigs JB, Wilson PW, Levy D. Glycemic status and development of kidney disease: the Framingham Heart Study. Diabetes Care. 2005;28(10):2436-40. [PubMed: 16186276].

45. Saber A, Fotuhi F, Rostami Z, Einollahi B, Nemati E. Vitamin D Levels After Kidney Transplantation and the Risk of Cytomegalovirus Infection. Nephro Urol Mon. 2015;7(6):ee29677. .

46. Futohi F, Saber A, Nemati E, Einollahi B, Rostami Z. Human Leukocyte Antigen Alleles and Cytomegalovirus Infection After Renal Transplantation. Nephrourol Mon. 2015;7(6):ee31635. doi: 10.5812/numonthly.31635. [PubMed: 26866009]. 